\title{
Kajian Perancangan dan Evaluasi PLTMH Jorong Patamuan Kabupaten Pasaman dalam Mengatasi Kekurangan Listrik Pedesaan
}

\author{
Nusyirwan \\ Jurusan Teknik Mesin, Fakultas Teknik, Universitas Andalas, Padang, Indonesia
}

INFORMASI ARTIKEL

Sejarah Artikel:

Diterima Redaksi: 04 Agustus 2016

Revisi Akhir: 01 September 2016

Diterbitkan Online: 01 Oktober 2016

\section{KATA KUNCI}

Cross-flow

Turbine banki

Head

Pipe rapidly

KORESPONDENSI

E-mail: nusyirwan@ft.unand.ac.id

\section{A B S T R A C T}

\begin{abstract}
Electrical energy supply which is not evenly distributed throughout the territory of Indonesia is mainly due to the width of the area the limitation on the budget. This condition has enforcing the rural residents to make their own electric energy generation. The discovery of a compact electric generator with control equipment that is reliable in a variety of sizes and power capacities has increasing the development of small size hydro electric power plants. One of the technology challenges for this power plant is to design a power plant with the existing water resources and equipment available on the market. Base on the preliminaries study in MHP Jorong Patamuan, it is found that the cross-flow turbines with a maximum power of $10 \mathrm{Kw}$ is more appropriate for the electrical generator. The Maximum head for this micro hydro generator is 8 meters and the net loss of $0.4 \mathrm{~m}$. The main channel is composed of a trunk made of concrete channels open with a size of $40 \times 40 \times 40 \mathrm{~cm}$ and a pipeline for rapid pipeline with a length of $28 \mathrm{~m}$ using the pipe 8 inches or $20 \mathrm{~cm}$. Generator been Generator one Phase with $10 \mathrm{Kw}$ power. There are constraints in this PLMH operation, which is the state annual river discharge decreased during July and August due to the long dry season so that the water flow is only $0.08 \mathrm{~m} 3 / \mathrm{s}$, far below the planned discharge $0.2252 \mathrm{~m} 3 / \mathrm{s}$ for the power wat 3000 output only approximately $1 / 3$ of the nominal power 10000 watt than planned.
\end{abstract}

\section{PENDAhuluan}

\subsection{Latar Belakang}

Distribusi energi listrik yang belum merata di seluruh Indonesia dengan keterbatasan anggaran negara memasaksa penduduk pedesaan untuk membuat sendiri sumber energi listriknya untuk penerangan dan kepentingan umum seperti rumah ibadah. sekolah dan sarana umum untuk membuat sumber energi listrik sendiri. Beberapa alternatif adalah dengan genset dan mikrohidro. Sumber energi dengan bahan bakar minyak cukup memberatkan bagi masyarakat karena biayanya yang cukup tinggi. Beberapa sumber daya yang dimanfaatkan diantaranya adalah potensial tenaga air pada umumnya beberapa pedesesaan sumber daya airnya cukup tersedia dan melimpah. Dengan kemajuan teknologi ditemukannya generator listrik yang kompak dengan peralatan kontrol dengan kehandalan yang cukup tinggi dengan berbagai macam ukuran dan kapasitas daya yang tersedia.

Salah satu tantangan teknologi adalah dapat merancang pembangkit listrik tenaga air dengan kemampuan memilih dan menyesuaikan rancangan pembangkit listrik dengan sumber daya air yang ada 
dan peralatan yang tersedia di pasaran. Salah satu yang menjadi kajian pada penelitian ini adalah membuat pembangkait energi listrik mikrohidro dengan daya $10 \mathrm{Kw}$ untuk Jorong patamuan Nagari Muaro Sungai LoloK kecamatan Mapet Tunggul Selatan Kabupataen Pasaman. Sungai yang diambil adalah anak sungai Batang Kampar yang berada pada Daerah aliran Sungai (DAS) Rokan -Indragiri yang bermuara ke Propinsi Riau. Sungai tersebut sangat potensial karena debit airnya masih diannggap stabil, karena berada pada kawasan Hutan Lindung Bukit-Barisan. Dengan Kerjasama UNDP, Dinas Kehutanan SUMBAR dan Universitas Andalas dibuat pembangkit listrik dengan dana yang bersumber dari UNDP tersebut.

\subsection{Tujuan}

Tujuan yang diharapkan dapat tercapai dari penelitian ini adalah: (1) Menentukan besarnya sumber daya air yang tersedia dengan kebutuhan listrik untuk penerangan rumah penduduk; (2) Menganalisa karakteristik pemakaian beban energi listrik di pedesaan khususnya Jorong Patamuan Kab. Pasaman.

\subsection{Manfaat}

Melalui penelitian ini dapat dibuat suatu pembangkit listrik tenaga air mikro hidro untuk kebutuhan penerangan penduduk dan juga salah satu pusat pengembangan pembangkit listrik untuk pengabdian masyarakat bagi perguruan tinggi khususnya Jurusan Teknik Mesin Fakultas Teknik Universitas Andalas.

\subsection{Ruang Lingkup Pembahasan}

Penelitian difokuskan untuk mengetahui berapa besarnya daya mekanik yang dapat diperoleh dari energi air yang tersedia dari sungai dan memprediksi jumlah energi listrik yang dapat didistribusikan ke perumahan penduduk. Pembahasan mencakup perhitungan head yang tersedia pada saluran pembawa dan saluran jatuh ke turbin dengan meminimumkan kerugian dari energi potensial air. Pemilihan jenis saluran dan lebar penampang salurun dan perhitungan kerugiam akibat belokan merupakan hal pokok dipertimbangkan. Hal berikutnya yang sangat perludipertimbangkan adalah penempatan lokasi rumah Turbin (Power House) yaitu dipilih pada lokasi yang terletak di permukaan yang rata dari tebing dan berada sekitar 2,5 m diatas permukaan sungai. Berdasarkan informasi dari masyarakat setempat, lokasi rumah turbin yang di pilih belum pernah mengalami banjir. Jarak perumahan penduduk Jorong Patamuan dengan lokasi PLTMH kurang lebih 2,5 km. Pada Gambar 1 diperlihatkan peta PLTMH yang diperoleh dari GPS.

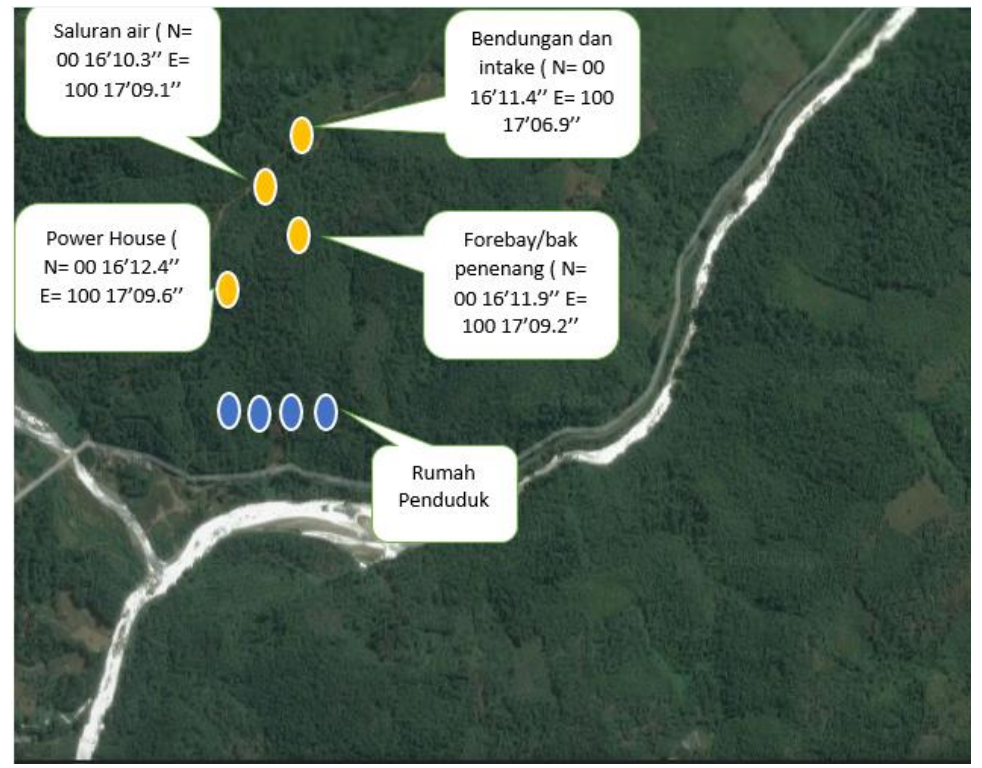

Gambar 1. Peta GPS Lokasi Bagian-Bagian PLTMH Jorong Patamuan 


\section{KAJIAN PUSTAKA}

\subsection{Kajian Potensial Energi Listrik}

Pembangkit listrik tenaga air yang banyak digunakan oleh masyarakat pedesaan adalah pembangkit listrik jenis mikro hidro (PLTMH) dengan daya maksimal $100 \mathrm{Kw}$. Prinsip kerja dari PLTMH adalah memanfaatkan debit air yang berasal dari sungai besar, sungai menengah maupun kecil dengan debit yang besar sampai debit yang sangat kecil sekitar 10 liter/detik dengan ketinggian jatuh 2 sampai $100 \mathrm{~m}$ [1]. Sumber daya air tersebut akan disalurkan dengan saluran tersendiri dan ditampung oleh bak penenang untuk pengkondisian tertentu dan dialirkan untuk memutar turbin dan generator yang menghasilkan energi listrik.

Beberapa komponen PLTMH adalah bendungan, saluran pembawa,bak penampung saluran jatuh dan turbin. Turbin adalah suatu peralatan mekanik yang dapat mengubah energi potensial air berupa ketinggian (Head) menjadi energi mekanik berupa tosi pada sudu turbin sehingga menghasilkan putaran pada poros turbin [2]. Besarnya putaran pada poros tergantung pada energi dari air dan dimensi turbin. Turbin air dapat dikelompokkan menjadi dua jenis yaitu turbin impuls dan turbin reaksi.

\subsection{Prinsip Kerja Turbin Crossflow}

Turbin Cross flow adalah radial, turbin bertekanan kecil dengan injeksi tangensial dari putaran kipas dengan poros horisontal. Turbin ini digolongkan sebagai turbin berkecepatan rendah. Aliran air mengalir melalui pintu masuk pipa, dan diatur oleh baling-baling pemacu dan masuk ke putaran kipas turbin. Setelah air melewati putaran kipas turbin, air berada pada putaran kipas yang berlawanan, sehingga memberikan efisiensi tambahan [3]. Akhirnya, air mengalir dari casing baik secara bebas atau melalui tabung dibawah turbin seperti diperlihatkan pada Gambar 2.

Persamaan kontinuitas dasar dari aliran fluida pada suatu penampang pipa yang berbentuk lingkaran
[5]. Pada kasus untuk penampang masuk (1) dan penampang keluar (2) adalah sebagai berikut:

$Q_{1}=Q_{2}$

atau

$A_{1} V_{1}=A_{2} V_{2}$

Bilangan Renold untuk aliran dalam pipa dapat dituliskan sebagai berikut:

$$
R_{e}=\frac{V D}{v}
$$

Kecepatan teroritis aliran dinyatakan oleh:

$V_{t}=\sqrt{2 \cdot g \cdot H}$

Besarnya kerugian Head Losses akibat gesekan dapat dihitung sebagai berikut:

$$
H l_{1}=f \frac{L}{D} \frac{V^{2}}{2 g}
$$

Besarnya kerugian Head Losses akibat belokan adalah:

$$
H l_{2}=k \frac{V^{2}}{2 g}
$$

Besarnya kerugian Head Losses akibat turbin banki dilengkapi dengan nozzle adalah:

$$
H l_{2}=\left(1 / c_{v}-1\right) \frac{V^{2}}{2 g}
$$

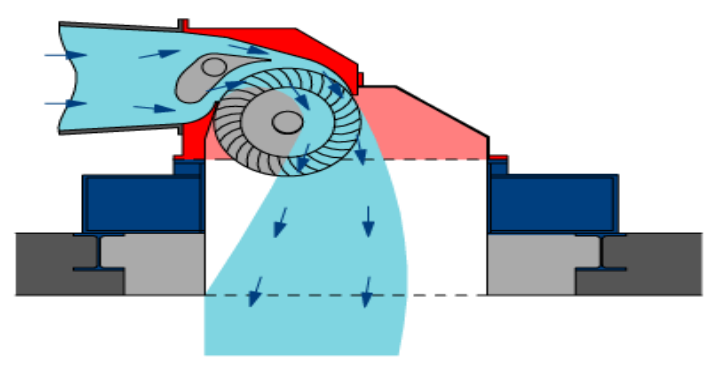

Gambar 2. Penurunan Tekanan Aliran Fluida Pada Sisi atas Turbin

Energi mekanik fluida yang akan diberikan ke turbin setelah dikurangi gesekan dan rugi-rugi 
lainnya yang dikenal dengan Water House Power (WHP)

$$
W H P=\rho . g \cdot Q \cdot H
$$

Daya yang diterima generator

$$
N_{g}=\rho \cdot g \cdot Q \cdot H \cdot \eta_{g} \cdot \eta_{t r s}
$$

\section{METODOLOGI PERANCANGAN DAN PENGUJIAN}

\subsection{Batasan Perancangan}

Penelitian ini bertujuan untuk mengetahui berapa besarnya daya mekanik yang dapat diperoleh akibat penurunan tekanan fluida terhadap jenis saluran yang dilalui oleh fluida pada saluran pembawadan saluran jatuh ke turbin dengan mempertimbangkan kerugian minimum dari energi potensial air [5]. Pemilihan jenis saluran dan lebar penampang salurun dan belokan merupakan hal pokok yang sangat perlu dipertimbangkan. Pada Gambar 4 diperlihatkan instalasi dari PLTMH Patamuan.

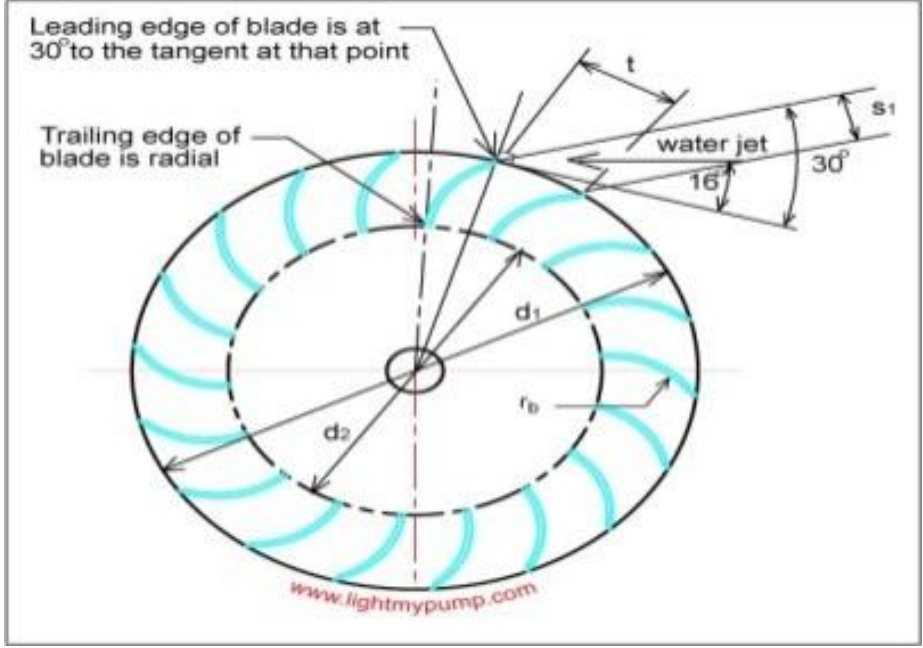

Gambar 3. Perhitungan aliran fluida pada sudu turbin

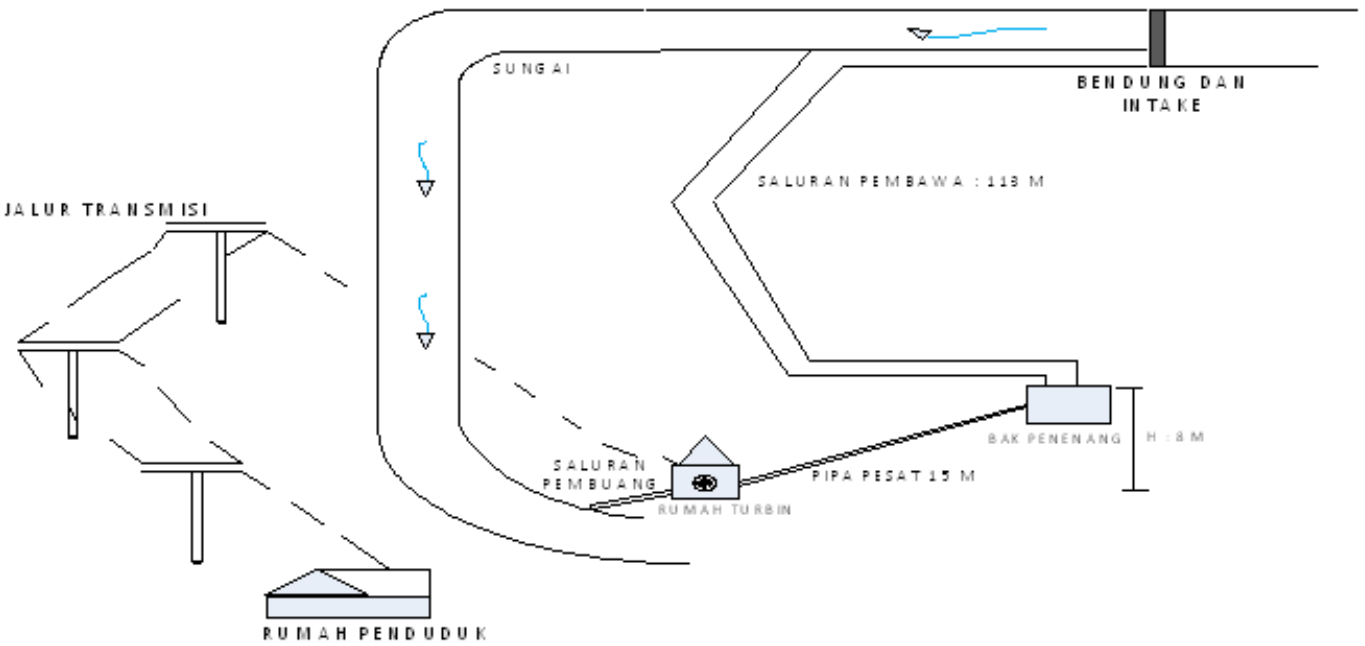

Gambar 4. Instalasi PLTMH Patamuan 


\subsection{Evaluasi dan Pembahasan Potensial Energi Mekanik pada PLTMH}

Dari hasil survey terhadap debit sungai yang tersedia dengan melakukan perhitungan terhadap luas penampang sungai dan menghitung kecepatan air,maka diperoleh debit air rata-rata [6]. Selain itu diperlukan hasil survey dengan mengambil kondisi air selama satu tahunan dan mencatat debit kritis yang paling terendah disebabkan musim kemarau yang panjang adalah antara bulan Juli sampai September dengan debit minimal 80 liter/detik selama lebih kurang 2 bulan, dihasilkan daya mekanik terendah 3000 watt. Daya ini lebih kurang hanya $1 / 3$ dari debit yang direncanakan yaitu 10.000 watt.

Debit air yang dihasilkan oleh PLTMH Patamuan seperti terlihat pada Gambar 6 berada jauh dibawah debit nominal sebesar $0.32 \mathrm{~m}^{3} / \mathrm{s}$ yang merupakan harga minimum untuk keamanan operasi PLTMH. Berdasarkan kondisi ini PLTMH yang dirancang lebih cocok menggunakan turbin jenis Cross Flow atau turbin aliran silang.

Berdasarkan hasil kalkulasi maka dipilih generator $10 \mathrm{KW}$ dengan asumsi efisiensi $80 \%$, Dalam praktek digunakan generator $10 \mathrm{KW}$ single phase.Turbin yang digunakan adalah jenis turbin Banki dengan berat $40 \mathrm{Kg}$ dan diameter Runner 40 $\mathrm{cm}$. Putaran $600 \mathrm{rpm}$.

Pada Gambar 7 diperlihatkan karakteristik pemakain beban pada rumah penduduk. Pada Gambar 7 tersebut terlihat bahwa pemakaian maksimum terjadi pada jam 5 sore sampai jam 10 malam.

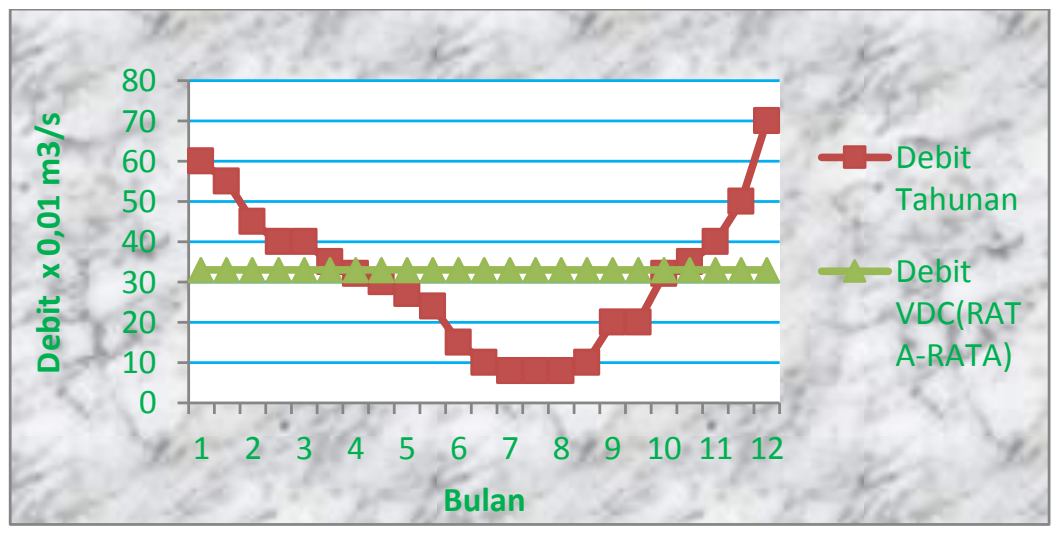

Gambar 5. Debit Tahunan dari Sungai Sumber Pembangkit PLTMH

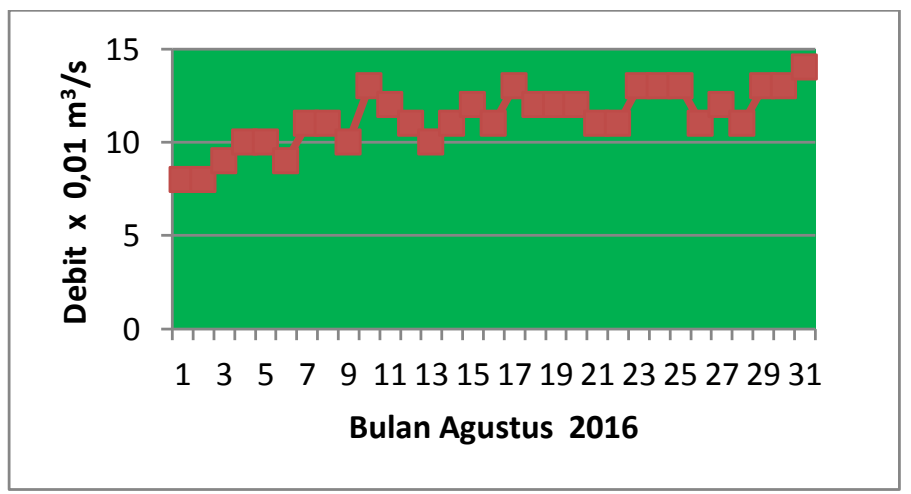

Gambar 6. Debit Sungai yang terukur pada Bulan Agustus 


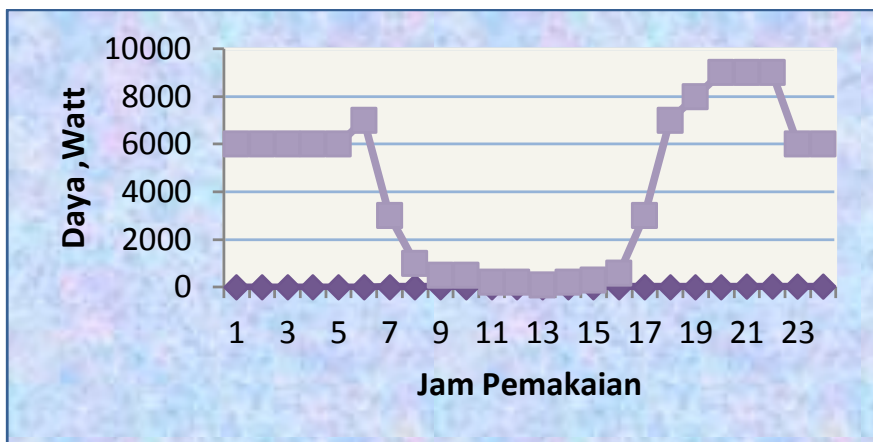

Gambar 7. Karakteristik Pemakaian Beban pada Rumah Penduduk

Berdasarkan data-data yang diperoleh maka dilakukan perancangan turbin. Pada Tabel 1 diperlihatkan parameter turbin hasil perancangan.

Tabel 1. Hasil Perancangan PLTMH Jorong Patamuan

\begin{tabular}{|c|l|l|}
\hline No & \multicolumn{1}{|c|}{ Parameter } & \multicolumn{1}{|c|}{ SATUAN } \\
\hline 1 & Debit Rata-rata yang tersedia Vdc & $0,32 \mathrm{~m}^{3} / \mathrm{s}$ \\
\hline 2 & Debit yang diperlukan & $0,2252 \mathrm{~m}^{3} / \mathrm{s}$ \\
\hline 3 & Head Maksimal & $8 \mathrm{~m}$ \\
\hline 4 & Daya Mekanik Air & $12614 \mathrm{watt}$ \\
\hline 4 & Daya Elektrik & 10.000 watt \\
\hline 5 & Diameter Pipa Saluran Turbin & 8 inchi \\
\hline 6 & Panjang saluran & $114 \mathrm{~m}$ \\
\hline 7 & Debit terendah pada musim panas & $0,008 \mathrm{~m}^{3} / \mathrm{s}$ \\
\hline
\end{tabular}

\section{KESIMPULAN}

Setelah dilakukan perancangan turbin untuk PLTMH Patamuan, maka diperoleh kesimpulan sebagai berikut: (1) Debit aliran yang tersedia pada sepanjang tahun adalah $0,32 \mathrm{~m}^{3} / \mathrm{s}$, tapi ini hanya berlangsung dari bulan Oktober sampai bulan Juli. Pada Bulan Agustus terjadi debit paling rendah dengan debit hanya $0,08 \mathrm{~m}^{3} / \mathrm{s} 1 / 3$ dibawah debit nominal sebesar $0,2252 \mathrm{~m}^{3} / \mathrm{s}$, sehingga daya yang dihasilkan hanya sekitar 3000 watt, sepertiga daya yang direncanakan; (2) Karakteristik pemakai beban adalah maksimal pada jam 17.00 sampai jam 22.00 sampai 9000 watt dan pada siang hari mulai jam 7.00 pagi sampai 16.00 hanya sekitar 400 watt; (3) Jenis turbin yang dipilih adalah jenis turbin Banki dengan mengacu ke yang lebih baik dengan jenis turbin aliran silang atau turbin cross flow dengan daya maksimal $10 \mathrm{Kw}$. Head Maksimal 8 meter dikurangi kerugian 0,4 m; (4) Saluran utama terdiri dari saluran induk yang terbuat dari saluran beton terbuka dengan ukuran 40 x 40 x $40 \mathrm{~cm}$ dan saluran pipauntuk saluran pipa pesat dengan panjang $28 \mathrm{~m}$ dengan memakai pipa paralon 8 inchi atau $20 \mathrm{~cm}$; (5) Generator dipilih Generator satu Phase dengan daya $10 \mathrm{Kw}$.

\section{DAFTAR PUSTAKA}

[1] F. M. White. Fluid Mechanic. Singapore: McGraw-Hill, 1994, pp. 30-50.

[2] F. Dietzel. Turbin, Pompadan Kompresor. Jakarta: Erlangga, 1995, pp. 15-50.

[3] L. A. Haimerl. The Cross Flow Turbine. Berlin, 1960, pp. 72-98.

[4] Sucipto. Petunjuk Operasional dan Perawatan PLTMH Sampot. Lumajang: CV. Hydro Cipta Mandiri, 2011, pp. 65-98.

[5] D. Sutikno. Turbin Air Banki. Malang: Teknik Mesin Universitas Brawijaya, 1997, pp. 299305.

[6] E. Y. Asrori. "Perencanaan Turbin Air Pembangkit Listrik Tenaga Mini Hidro (Studi Kasus Proyek PLTM Buleleng 2 x 600 kW)", dalam Prosiding Volume 3 Seminar Nasional Teknologi dan Aplikasinya, 2011, pp. 79-85.

\section{NOMENKLATUR}

$\mathrm{A}_{1,2} \quad$ Luas penampang saluran $1,2\left(\mathrm{~m}^{2}\right)$

$\mathrm{C}_{\mathrm{v}} \quad$ Koefesien kecepatan fluida (.)

D Diameter penampang

f Koefesien gesekan(.)

g Konstanta grafitasi $\left(10 \mathrm{~m} / \mathrm{s}^{2}\right)$ 
$\mathrm{H} \quad$ Head (M)

$\mathrm{H}_{1} \quad$ Head losses (m)

$\mathrm{k} \quad$ Koefesien belokan (.)

$\mathrm{Ng}$ Daya generator (watt)

Q Debit $\left(\mathrm{m}^{3} / \mathrm{s}\right)$

$\mathrm{R}_{\mathrm{e}} \quad$ Reinold Number

WHP Water House Power (watt)

\section{Greek letters}

$\eta_{g} \quad$ Efisiensi generator (.)

$\eta_{t r s} \quad$ Efisiensi transmisi (.)

$\rho \quad$ Berat jenis air $\left(1000 \mathrm{~kg} / \mathrm{m}^{3}\right)$ 